\title{
Investigation on the structural and magnetic properties of sputtered $\mathrm{TbFe}_{2} / \mathrm{Fe}_{3} \mathrm{Ga}$ heterostructures
}

\author{
R. Ranchal ${ }^{\text {a) }}$ and V. González-Martín \\ Dpto. Física de Materiales, Fac. CC. Físicas, Universidad Complutense de Madrid, Ciudad Universitaria s/n, \\ Madrid 28040, Spain
}

(Received 27 April 2011; accepted 17 July 2011; published online 1 September 2011)

\begin{abstract}
We have analyzed the structural and magnetic properties of as-grown and annealed $\left[\mathrm{TbFe}_{2} / \mathrm{Fe}_{3} \mathrm{Ga}\right]_{n}$ heterostructures grown by sputtering. Evidence of the bcc structure in the $\mathrm{Fe}_{3} \mathrm{Ga}$ layers has been found. The diffraction peak related to this structure shifts to high angles with the annealing temperature. Also, we have observed a change in the microstructure of the $\mathrm{Tb}-\mathrm{Fe}$ layers when the thickness layer is reduced in the as-grown heterostructures. Moreover, the Tb content is lower than $33 \%$ of the $\mathrm{TbFe}_{2}$ Laves phase and it depends on the layer thickness. The thermal treatments promote the increase of the $\mathrm{Tb}$ content, but only in the heterostructures with thick layers. The strong lattice mismatch between the $\mathrm{Tb}-\mathrm{Fe}$ and $\mathrm{Fe}-\mathrm{Ga}$ layers seems to prevent a complete $\mathrm{Tb}$ diffusion upon the annealing process. Thus, the crystallization of the $\mathrm{TbFe}_{2}$ Laves phase is inhibited in the heterostructures with thin layers, although our experimental results indicate the presence of potential magnetostrictive TbFeGa alloys. (C) 2011 American Institute of Physics. [doi:10.1063/1.3626070]
\end{abstract}

\section{INTRODUCTION}

In the past years, there has been an increasing interest in magnetostrictive materials because of their great potential in a variety of applications such as magnetic actuators or sensors. The discovery of the magnetostriction increase of $\mathrm{Fe}$ upon its doping with Ga (Ref. 1) boosted the investigations of $\mathrm{Fe}_{1-\mathrm{x}} \mathrm{Ga}_{\mathrm{x}}$ alloys. Advanced characterization techniques have been used to analyze the strong correlation between the microstructure and the magnetoelastic properties in this material system..$^{2-7}$ These studies have proved that it is essential to precisely control the structural ordering in order to achieve a magnetostriction constant $(\lambda)$ of around $400 \mathrm{ppm}$ in crystalline and $280 \mathrm{ppm}$ in polycrystalline bulk Galfenol samples. ${ }^{89}$ These high magnetostriction constants are achieved in quenched samples with Ga contents of $19 \%$ and $28 \%$. However, the $\lambda$ of the $\mathrm{Fe}-\mathrm{Ga}$ alloys is one order of magnitude lower than that of crystalline $\mathrm{TbFe}_{2}$, the material with the highest magnetostriction at room temperature, $2500 \mathrm{ppm}^{10}$ The high coercivity of its crystalline phase, $\sim 4 \mathrm{kOe}$, prevents its use in industrial applications. ${ }^{11}$ However, Galfenol has a much lower coercivity than $\mathrm{TbFe}_{2}$. Therefore, heterostructures consisting of a combination of both Fe-Ga alloys and $\mathrm{TbFe}_{2}$ appear to be promising candidates for the development of a new era of magnetic sensors. Moreover, few works have been devoted to the investigation of $\mathrm{Fe}_{1-\mathrm{x}} \mathrm{Ga}_{\mathrm{x}}$ thin films. ${ }^{12-16}$ In a previous work, we studied the characteristics of $\mathrm{Tb}_{\mathrm{x}} \mathrm{Fe}_{1-\mathrm{x}}$ thin films. ${ }^{17}$ In this work, we analyze and correlate the structural and magnetic properties of as-grown and annealed $\left[\mathrm{TbFe}_{2} / \mathrm{Fe}_{3} \mathrm{Ga}\right]_{\mathrm{n}}$ heterostructures.

\footnotetext{
a) Author to whom correspondence should be addressed. Fax: + 34913944547. Electronic mail: rociran@fis.ucm.es.
}

\section{EXPERIMENTAL TECHNIQUES}

Samples were grown by a magnetron sputtering system on glass substrates. In all of the heterostructures, the thickness of the $\mathrm{TbFe}_{2}$ and $\mathrm{Fe}_{3} \mathrm{Ga}$ layers is the same, ranging from $12.5 \mathrm{~nm}$ to $200 \mathrm{~nm}$. It has been necessary to adjust the number of $\mathrm{TbFe}_{2} / \mathrm{Fe}_{3} \mathrm{Ga}$ bilayers (n) in order to achieve the same total thickness $(400 \mathrm{~nm})$ in all of the heterostructures. The Ar pressure was $2 \times 10^{-3}$ mbar during the growth of the magnetostrictive layers, with a power of $120 \mathrm{~W}$ for the deposition of the $\mathrm{TbFe}_{2}$ and $100 \mathrm{~W}$ for the $\mathrm{Fe}_{3} \mathrm{Ga}$ layers. Mo buffer and capping layers $20 \mathrm{~nm}$ thick were used to protect the heterostructures against oxidation. They were grown with a dc power of $90 \mathrm{~W}$ and at an Ar pressure of $2 \times 10^{-3}$ mbar. The structural properties were determined by means of x-ray diffractometry (XRD) using a Philips MPD system. The magnetic measurements were carried out in a vibrating sample magnetometer at room temperature. The temperature dependence of the magnetization has been characterized by means of SQUID magnetometry. Prior to measuring the temperature dependence of the magnetization, the sample was first cooled from room temperature to $5 \mathrm{~K}$ either under a saturation field of $5 \mathrm{kOe}$ (field-cooled $[\mathrm{FC}]$ ) or at zero field (zero-field-cooled $[\mathrm{ZFC}]$ ). Then, FC and ZFC curves were recorded with an applied magnetic field of 100 Oe during the warming-up. Thermal treatments were carried out in $\mathrm{Ar}$ atmosphere over $1 \mathrm{~h}$ in a temperature range between $300{ }^{\circ} \mathrm{C}$ and $400{ }^{\circ} \mathrm{C}$. After the annealing, samples were cooled down at a rate of $20^{\circ} \mathrm{C} / \mathrm{min}$.

\section{EXPERIMENTAL RESULTS AND DISCUSSION}

XRD measurements reveal the presence of diffraction peaks of both cubic $\mathrm{TbFe}_{2}$ and body centered cubic (bcc) phases of $\mathrm{Fe}(\alpha-\mathrm{Fe})$ (Fig. 1). The crystalline cubic Laves phase is related to the large magnetostriction constant of 

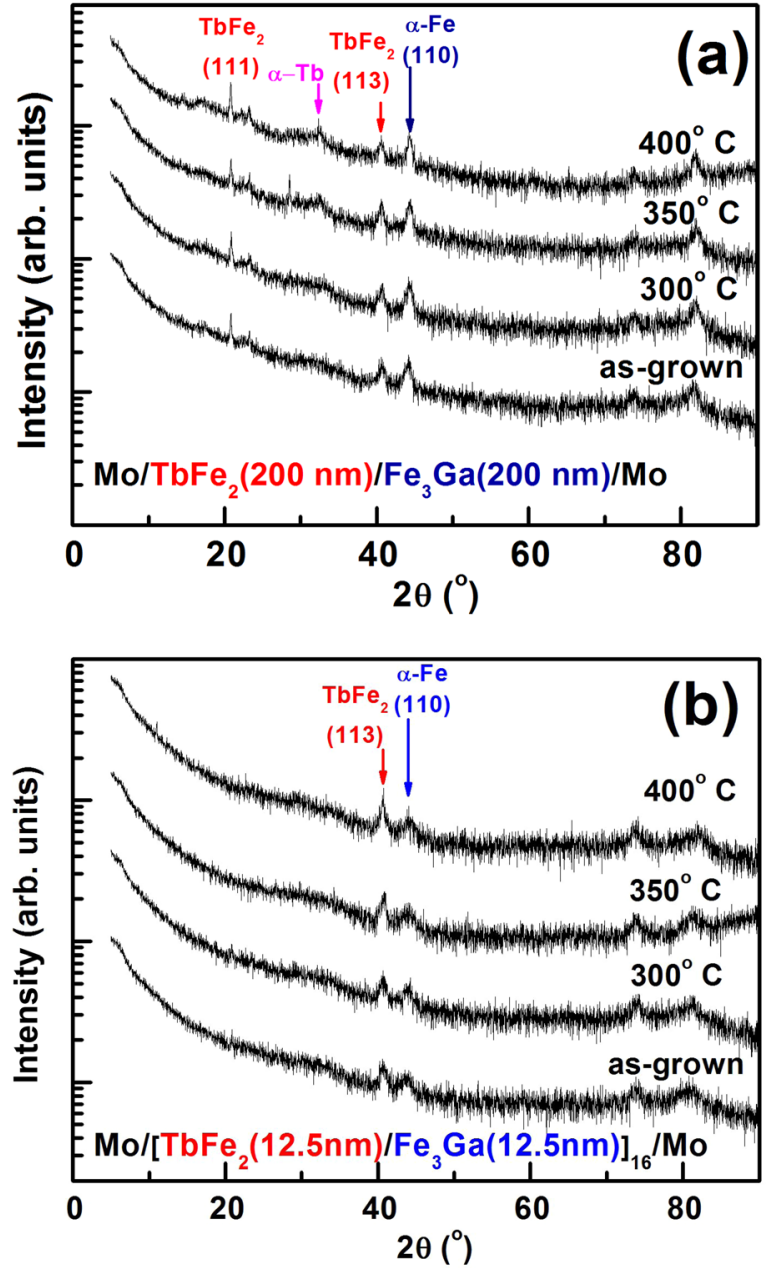

FIG. 1. (Color online) X-ray diffractometry scans of as-grown heterostructures and heterostructures annealed at different temperatures. (a) $\left[\mathrm{TbFe}_{2}(200\right.$ $\left.\mathrm{nm}) / \mathrm{Fe}_{3} \mathrm{Ga}(200 \mathrm{~nm})\right]$. (b) $\left[\mathrm{TbFe}_{2}(12.5 \mathrm{~nm}) / \mathrm{Fe}_{3} \mathrm{Ga}(12.5 \mathrm{~nm})\right]_{16}$.

$2500 \mathrm{ppm}$ at room temperature of the $\mathrm{TbFe}$ system. The $\mathrm{TbFe}_{2}(113)$ diffraction peak is observed in all of the heterostructures, regardless of the thickness and the annealing temperature. Moreover, the heterostructures with thick layers exhibit a diffraction peak that shows the presence of the $\alpha$-Tb phase [Fig. 1(a)]. In a previous work about the crystallization of $\mathrm{TbFe}_{2},{ }^{17}$ we demonstrated that the formation of this phase is closely related to an optimum crystallization of the $\mathrm{TbFe}_{2}$ Laves phase.

The presence of the $\alpha$-Fe peak can be taken as evidence of the bcc structure related to either the disordered $\mathrm{A} 2$ or ordered $\mathrm{D}_{3}$ phases. The former (A2) is strongly correlated with the magnetostriction of around $400 \mathrm{ppm}$ in the $\mathrm{Fe}_{1-\mathrm{x}} \mathrm{Ga}_{\mathrm{x}}$ alloys. ${ }^{3,18,19}$ Following the work of Cao et al., ${ }^{3}$ we can investigate the presence of $\mathrm{D}_{3}$ precipitates by means of the (100) and (111) superlattice reflections, which are not allowed for the A2 structure. We have not found such reflections around $2 \theta \sim 30.75^{\circ}$ or $2 \theta \sim 64^{\circ}$ in any of our heterostructures [Figs. 1(a) and 1(b)]. Nevertheless, it is important to mention a few aspects. First of all, the $\mathrm{D}_{3}$ precipitates can be so small that they cannot be detected by means of XRD characterization. Second, the studied heterostructures are rather polycrystalline, which complicates the detection of different phases. Finally, our samples are sputtered films that are as-grown and
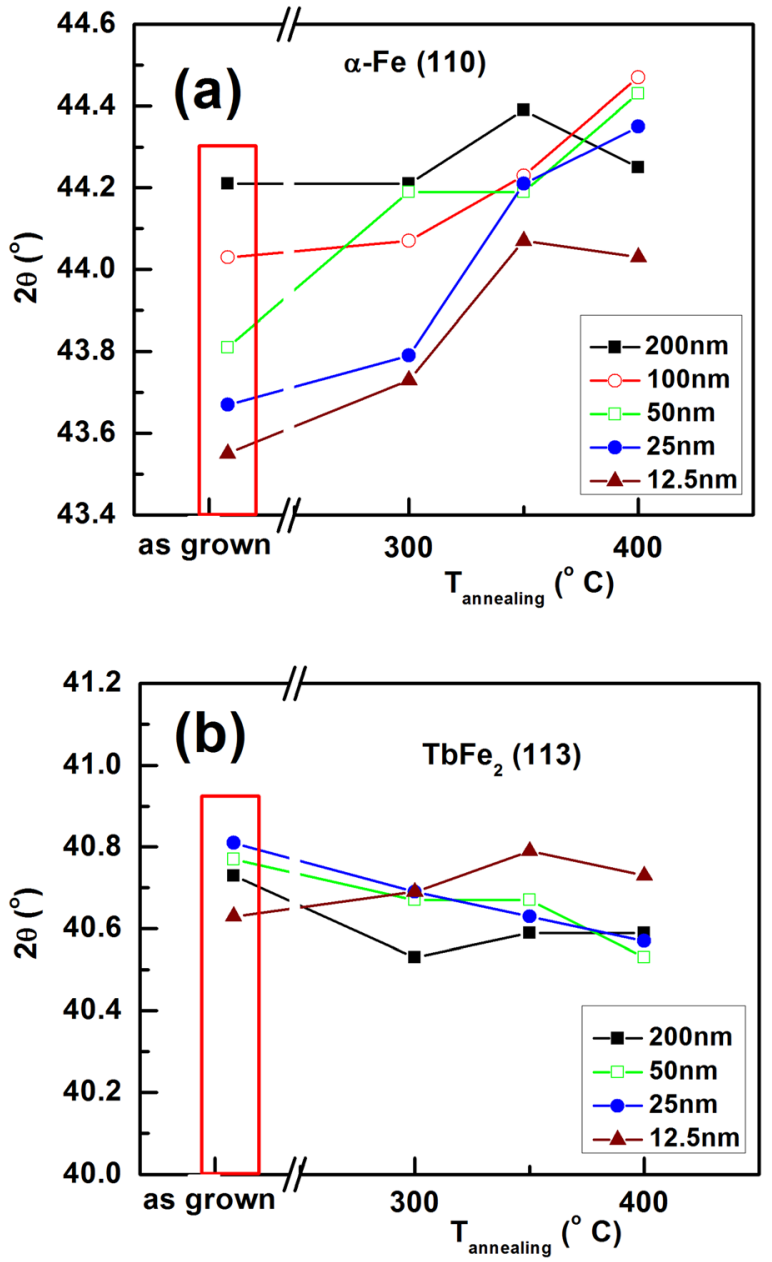

FIG. 2. (Color online) (a) $\alpha-\mathrm{Fe}(110)$ and (b) $\mathrm{TbFe}_{2}(113)$ diffraction angle as a function of the annealing temperature for heterostructures with different layer thicknesses: $\square, 200 \mathrm{~nm} ; \bigcirc, 100 \mathrm{~nm} ; \square, 50 \mathrm{~nm} ; \bullet, 25 \mathrm{~nm} ; \boldsymbol{\Delta}, 12.5 \mathrm{~nm}$.

annealed at low temperatures, and so they might have a different microstructure than the bulk crystalline high-temperature annealed samples studied in previous works. ${ }^{2-7,18,19}$ Taking into account all of these aspects, we can indicate that our experimental results point to a cubic structure in the $\mathrm{Fe}_{3} \mathrm{Ga}$ layers, being not observed evidences of the $\mathrm{D}_{3}$ phase.

In Figs. 2(a) and 2(b), we plot the evolution of the two most important diffraction peaks observed in the XRD scans, $\mathrm{TbFe}_{2}(113)$ and $\alpha-\mathrm{Fe}(110)$, as a function of the annealing temperature. From these plots, we cannot infer conclusive results about the $\mathrm{TbFe}_{2}$, whereas the tendency is clearer for the $\mathrm{Fe}_{3} \mathrm{Ga}$ layers. There is a shift of the (110) $\alpha$-Fe diffraction peak to high angles, promoted by the annealing temperature being more pronounced in the heterostructures with thin layers. This shift can be due to either the mismatch between the thermal expansion coefficient $(\alpha)$ of the different materials (layers, buffer, and/or substrate) or the decrease of the $\mathrm{Fe}_{3} \mathrm{Ga}$ layer lattice parameter for another reason. $\mathrm{TbFe}_{2}$ and $\mathrm{Fe}_{3} \mathrm{Ga}$ have pretty similar $\alpha$ values $-12 \times 10^{-6} \mathrm{~K}^{-1}$ and $17 \times 10^{-6} \mathrm{~K}^{-1}$, respectively - and so they are not expected to produce any effect on each other. Both Mo $\left(\alpha=5 \times 10^{-6} \mathrm{~K}^{-1}\right)$ and glass $\left(\alpha=2 \times 10^{-6} \mathrm{~K}^{-1}\right)$ have lower $\alpha$ values in comparison to $\mathrm{Fe}_{3} \mathrm{Ga}$, and so they could promote compressive stresses on the heterostructures. Nevertheless, the influence 
of the annealing temperature on the lattice parameter suggests the necessity of taking into account more effects in order to fully explain the observed behavior.

We have performed FC-ZFC routines to further analyze the characteristics of the heterostructures. In our previous work about the microstructure of $\mathrm{Tb}_{\mathrm{x}} \mathrm{Fe}_{1-\mathrm{x}}$ films, ${ }^{17}$ the presence of a cusp in the ZFC curves was an indication of the existence of nanoaggregates in the as-grown $\mathrm{Tb}_{\mathrm{x}} \mathrm{Fe}_{1-\mathrm{x}}$ thin films. As an example, we present in this work the ZFC curve of a 25 $\mathrm{nm}$ thick $\mathrm{TbFe}_{2}$ single layer deposited under the same growth conditions as the samples studied in this work [Fig. 3(a)].
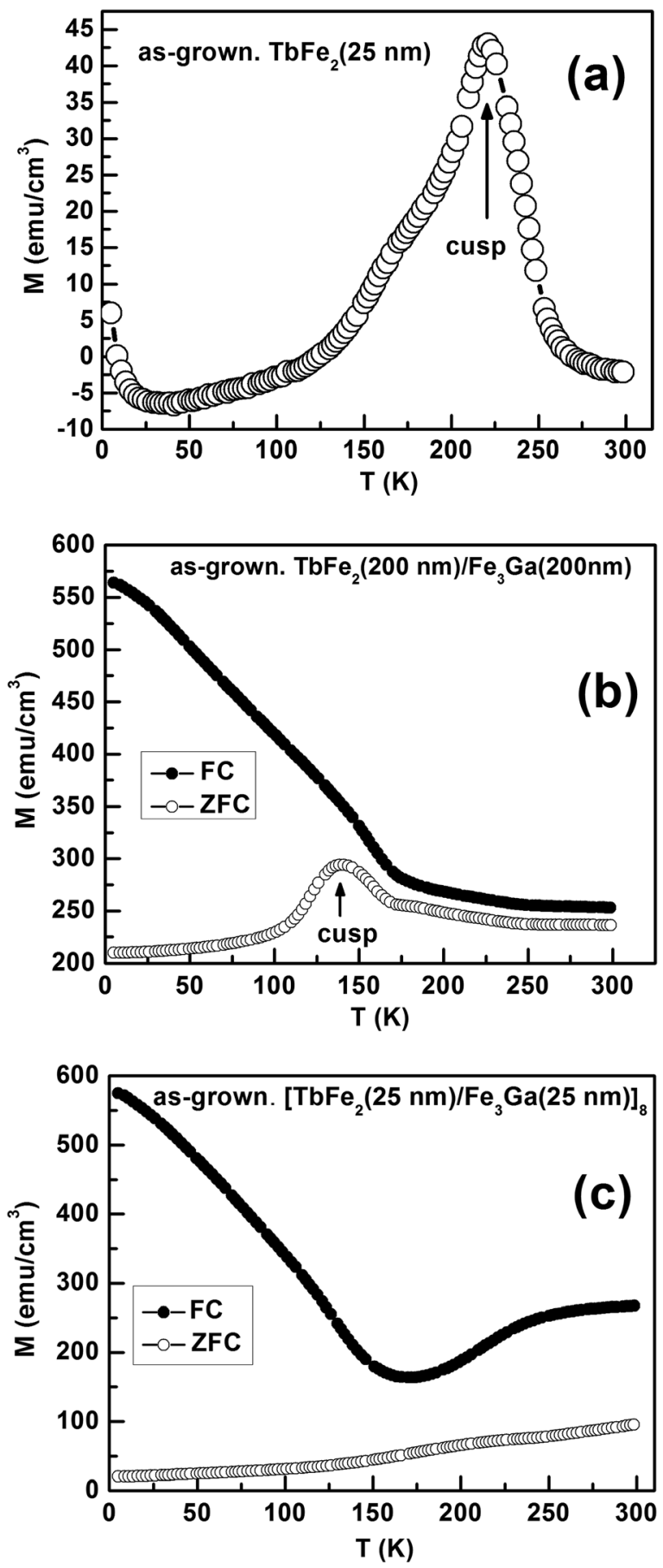

FIG. 3. (a) ZFC curve of a $\mathrm{TbFe}_{2}$ single layer with a thickness of $25 \mathrm{~nm}$. $\mathrm{FC}$ and ZFC curves of as-grown heterostructures: (b) [TbFe2(200 nm)/ $\mathrm{Fe} 3 \mathrm{Ga}(200 \mathrm{~nm})]$ and $(\mathrm{c})\left[\mathrm{TbFe}_{2}(25 \mathrm{~nm}) / \mathrm{Fe}_{3} \mathrm{Ga}(25 \mathrm{~nm})\right]_{8}$.
ZFC-cusps are observed in the as-grown heterostructures having a layer thickness greater than $50 \mathrm{~nm}$ [Fig. 3(b)]. Samples with a layer thickness equal to or less than $50 \mathrm{~nm}$ do not exhibit these cusps, and so they have a completely different microstructure [Fig. 3(c)]. As the single $\mathrm{TbFe}_{2}$ film with a low thickness does present a ZFC-cusp [Fig. 3(a)], the change of the structural properties in the heterostructures with thin layers seems to be correlated with the influence of the $\mathrm{Fe}_{3} \mathrm{Ga}$ on the $\mathrm{TbFe}_{2}$ layers. Hereafter, we will denote as thin layers those with a thickness equal to or less than $50 \mathrm{~nm}$, and as thick layers those with a thickness greater than $50 \mathrm{~nm}$. Finally, it is noteworthy that none of the annealed heterostructures show ZFC-cusps, and so nanoaggregates are not promoted by the thermal treatments.

In the Tb-Fe alloys, there is a so-called compensation temperature $\left(\mathrm{T}_{\mathrm{Comp}}\right)$ due to the antiferromagnetic coupling between the $\mathrm{Tb}$ and $\mathrm{Fe}$ atoms. ${ }^{20}$ The $\mathrm{T}_{\mathrm{Com}}$ can be measured in the FC curves (Fig. 4), and at that temperature the total magnetization is at a minimum because the $\mathrm{Fe}$ and $\mathrm{Tb}$ magnetic moments are equal and have almost antiparallel directions because of the antiferromagnetic coupling. Tb-Fe alloys do not exhibit a zero magnetization at the $\mathrm{T}_{\mathrm{Com}}$, in contrast to other alloys of heavy rare-earths and magnetic transition metals with similar antiferromagnetic coupling, because there is not a complete antiparallel arrangement between $\mathrm{Tb}$ and $\mathrm{Fe}$ atoms. Mimura et al. $^{21}$ studied the
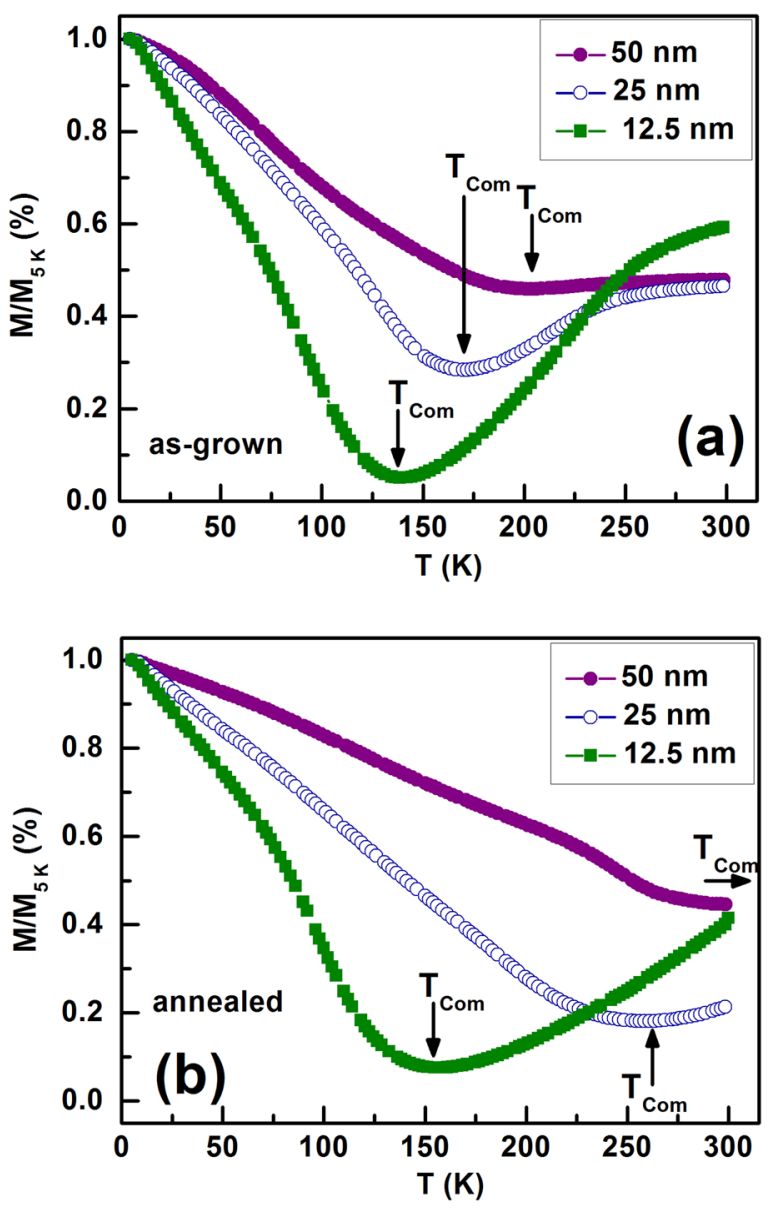

FIG. 4. (Color online) FC curves of heterostructures with different layers thickness. $\bullet, 50 \mathrm{~nm} ; \bigcirc, 25 \mathrm{~nm} ; \mathbf{\square}, 12.5 \mathrm{~nm}$. (a) As-grown. (b) Annealed. 

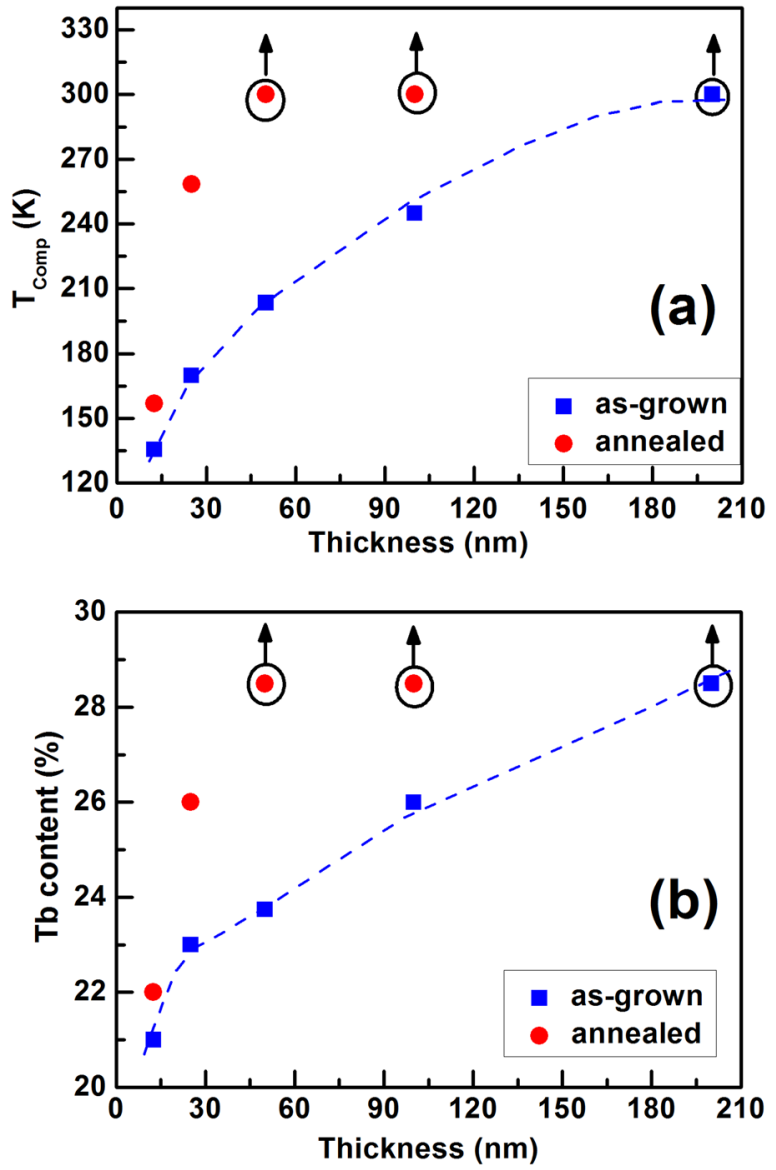

FIG. 5. (Color online) (a) $\mathrm{T}_{\mathrm{Com}}$ as a function of the layer thickness for the

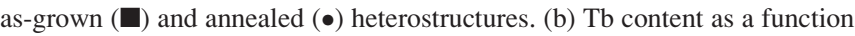
of the layer thickness for the as-grown (ם) and annealed $(\bullet)$ heterostructures. In these two graphs, the dashed lines are guides for the eye. The points that are surrounded with a circle represent the maximum values that we can experimentally determine. Thus, the actual values are equal to or higher than the points surrounded with a circle.

correlation between the composition and the $\mathrm{T}_{\mathrm{Com}}$ in amorphous Tb-Fe alloys. Therefore, we can use the work of Mimura et al. to analyze the composition and the influence of the thermal treatments on the Tb-Fe layers. However, it is necessary to take into account the fact that the microstructure of our Tb-Fe films is different from those of Mimura et al., as our samples are not amorphous. The investigation of the microstructure by means of advanced characterization techniques such as x-ray photoelectron spectroscopy could shed light on this aspect. However, that study is beyond the scope of the present work, and we use the work of Mimura et al. as a reference to infer the composition of the TbFe layers.

In Figs. 5(a) and 5(b), we present the $\mathrm{T}_{\mathrm{Com}}$ and the $\mathrm{Tb}$ content, respectively, as a function of the layer thickness for as-grown and annealed heterostructures. In those figures, we have surrounded with a circle those samples having a $T_{C o m}$ that is higher than $300 \mathrm{~K}$ [Fig. 5(a)], and it can be indicated only that the $\mathrm{Tb}$ content is equal to or higher than $28 \%$ [Fig. 5(b)]. We will first discuss the results related to the asgrown samples. The composition of the Tb-Fe layers in the heterostructures is different from that of the nominal $\mathrm{TbFe}_{2}$ [Fig. 5(b)]. As they were deposited under growth conditions that produce the $\mathrm{TbFe}_{2}$ composition, the decrease of the $\mathrm{Tb}$
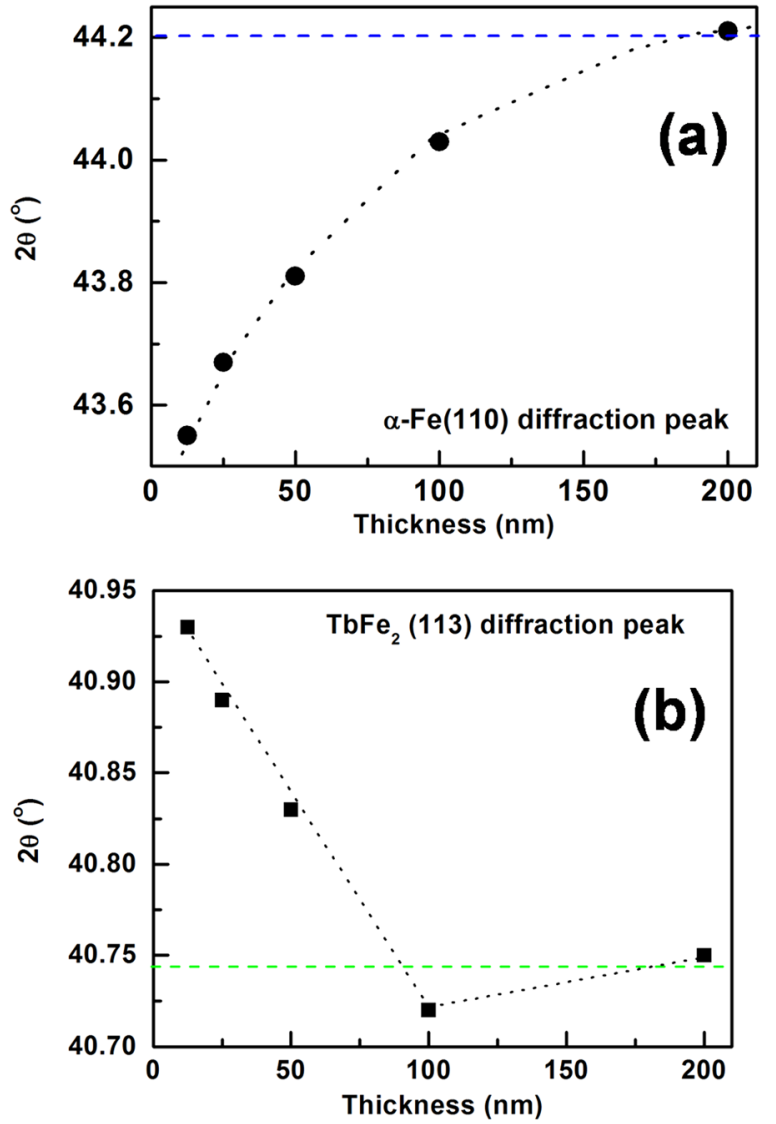

FIG. 6. (Color online) (a) Position of the $\alpha-\mathrm{Fe}(110)$ diffraction peak as a function of the layer thickness in the as-grown heterostructures. The (blue) dashed horizontal line indicates the position of the $\alpha$ - $\mathrm{Fe}(110)$ diffraction peak observed in the $\mathrm{Fe}_{3} \mathrm{Ga}$ single layer used as reference. The dotted line is a guide for the eye. (b) Position of the $\mathrm{TbFe}_{2}(113)$ diffraction peak as a function of the layer thickness in the as-grown heterostructures. The (green) dashed horizontal line indicates the position of this diffraction peak in a $\mathrm{TbFe}_{2}$ bulk sample. The dotted line is a guide for the eye.

content with the layer thickness seems to be related to the influence of the $\mathrm{Fe}_{3} \mathrm{Ga}$ layers. Therefore, the low $\mathrm{Tb}$ content in the heterostructures with thin layers can explain the absence of ZFC-cusps, as it has been already reported that in $\mathrm{Tb}_{\mathrm{x}} \mathrm{Fe}_{1-\mathrm{x}}$ films the nanoaggregate volume decreases when the $\mathrm{Tb}$ content is reduced. ${ }^{17}$ The $\mathrm{Tb}$ atoms not present in the Tb-Fe layers must diffuse to the $\mathrm{Fe}_{3} \mathrm{Ga}$ layers and/or the interfaces, and this process is more relevant in the as-grown heterostructures with thin layers. In Fig. 6 we show the position of the diffraction peaks related to the $\mathrm{Fe}_{3} \mathrm{Ga}$ and $\mathrm{Tb}-\mathrm{Fe}$ layers. The lower the diffraction angle, the higher the lattice parameter. The decrease (increase) of the $\mathrm{Fe}_{3} \mathrm{Ga}(\mathrm{Tb}-\mathrm{Fe}$ ) diffraction angle when the thickness is reduced points to the increase (decrease) of the $\mathrm{Fe}_{3} \mathrm{Ga}(\mathrm{Tb}-\mathrm{Fe}$ ) lattice parameter. These results are in agreement with the $\mathrm{Tb}$ diffusion observed in the magnetic characterization.

In the annealed heterostructures, it is observed that the $\mathrm{T}_{\mathrm{Com}}$ is shifted to higher temperatures, indicating an increase of the $\mathrm{Tb}$ content in the $\mathrm{Tb}-\mathrm{Fe}$ layers upon the thermal treatments [Figs. 4(b) and 5]. The Tb diffusion from the $\mathrm{Fe}_{3} \mathrm{Ga}$ layers and/or the interfaces promoted by the annealing process can explain this increase of the Tb content. Moreover, it can also account for the decrease of the lattice parameter of the $\mathrm{Fe}_{3} \mathrm{Ga}$ layers with the annealing temperature [Fig. 2(a)]. 
The $\mathrm{Tb}$ enrichment is more evident in the samples with thick layers [Fig. 5(b)]. There is a high lattice mismatch of around $61 \%$ (Ref. 22) between the $\mathrm{Tb}_{2} \mathrm{Fe}$ and the Fe-Ga alloys. The thinner the layer, the higher the strain promoted by the lattice mismatch. In heterostructures with thick layers, the strain can be gradually released along the layer thickness. In samples with thin layers, the strain must be released in different ways-for example, decreasing the $\mathrm{Tb}$ content in the $\mathrm{Tb}-\mathrm{Fe}$ layers or increasing the lattice parameter of the $\mathrm{Fe}_{3} \mathrm{Ga}$ layers by means of the introduction of $\mathrm{Tb}$ atoms into these layers and/or the interfaces. These two effects reduce the lattice mismatch across the heterostructure. Thus, it seems that the increase of the $\mathrm{Tb}$ content in the $\mathrm{Tb}$-Fe layers of heterostructures with low thicknesses is inhibited in order to prevent a large lattice mismatch and, thus, to reduce the strain. This incomplete $\mathrm{Tb}$ diffusion in these samples with low thicknesses can also explain the low Tb content achieved in those annealed heterostructures.

We have also measured the hysteresis loops at room temperature of the as-grown and annealed heterostructures. The magnetic behavior depends on the annealing temperature and on the layer thickness. Heterostructures with high thicknesses show two distinct ferromagnetic characteristics [Fig. 7(a)]: a ferromagnetic ordering with a low coercivity related to the $\mathrm{Fe}_{3} \mathrm{Ga}$, and a phase with a much higher coer-
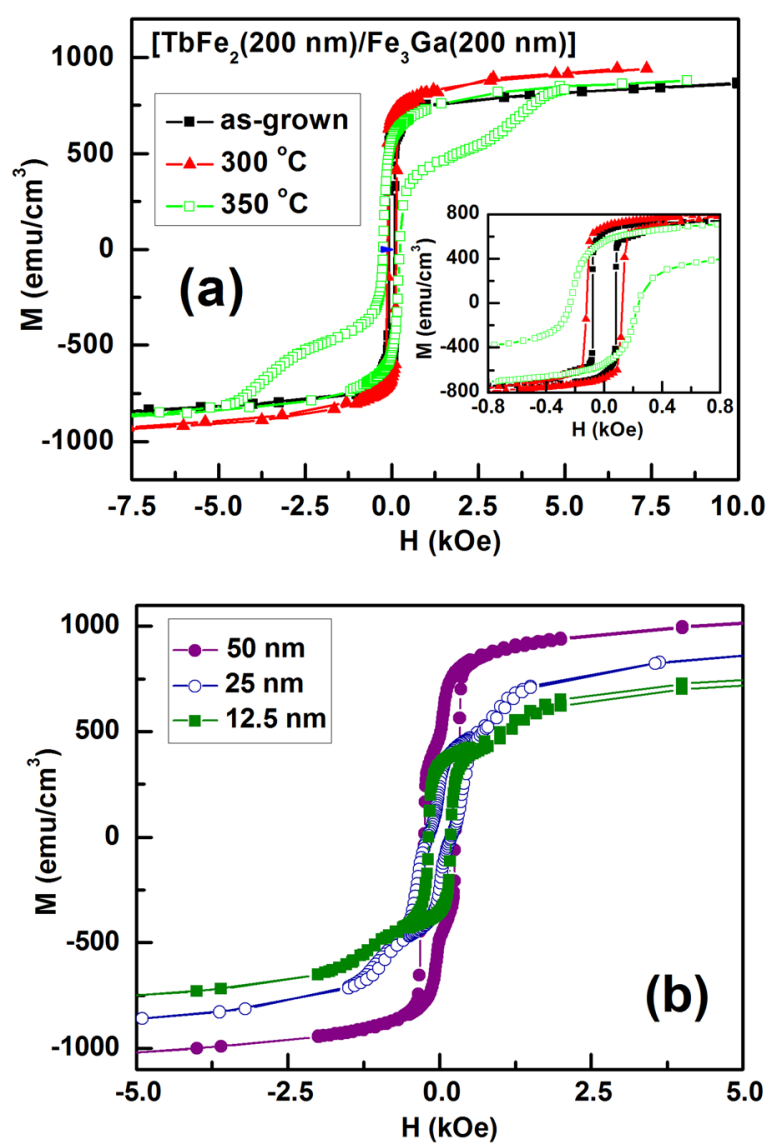

FIG. 7. (Color online) (a) Magnetic hysteresis loop at room temperature of the $\left[\mathrm{TbFe}_{2}\left(200 \mathrm{~nm} / \mathrm{Fe}_{3} \mathrm{Ga}(200 \mathrm{~nm})\right]\right.$ heterostructure for different annealing

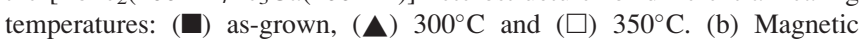
hysteresis loop at room temperature of annealed heterostructures: (•) $\left[\mathrm{TbFe}_{2}\left(50 \mathrm{~nm} / \mathrm{Fe}_{3} \mathrm{Ga}(50 \mathrm{~nm})\right]_{4}\right.$, (○) $\left[\mathrm{TbFe}_{2}\left(25 \mathrm{~nm} / \mathrm{Fe}_{3} \mathrm{Ga}(25 \mathrm{~nm})\right]_{8}\right.$, and (घ) $\left[\mathrm{TbFe}_{2}\left(12.5 \mathrm{~nm} / \mathrm{Fe}_{3} \mathrm{Ga}(12.5 \mathrm{~nm})\right]_{16}\right.$. civity of $4 \mathrm{kOe}$. In those samples, the composition of the $\mathrm{Tb}$-Fe layers is $\mathrm{TbFe}_{2}$, making it possible to crystallize the high coercivity Laves phase. This crystallization is in agreement with the structural and magnetic characterization already presented in this work. Heterostructures with thin layers show a completely different magnetic behavior. Regardless of the annealing temperature, we observe not the crystallized $\mathrm{TbFe}_{2}$ but another low coercivity material that becomes more relevant as the thickness is reduced [Fig. 7(b)]. We can correlate this magnetic behavior to the phase formed because of the presence of the $\mathrm{Tb}$ atoms at the $\mathrm{Fe}_{3} \mathrm{Ga}$ layers and/or the interfaces, and it should be a TbFeGa alloy. These alloys have been poorly studied, although it has been reported that they can exhibit a pretty high magnetostriction of around 1000 ppm. ${ }^{23}$ Thus, in the heterostructures with thin layers, the $\mathrm{TbFe}_{2}$ cannot be crystallized because of the low $\mathrm{Tb}$ content in the Tb-Fe layers. Nevertheless, our experimental results indicate the presence of another potential magnetostrictive phase. More studies are necessary in order to analyze the potential magnetoelastic properties of these novel heterostructures.

\section{CONCLUSIONS}

In conclusion, we have analyzed the structural and magnetic properties of $\left[\mathrm{TbFe}_{2} / \mathrm{Fe}_{3} \mathrm{Ga}\right]_{n}$ heterostructures. We have found evidence of a cubic structure in the $\mathrm{Fe}_{3} \mathrm{Ga}$ layers. The magnetic characterization shows that the $\mathrm{Tb}$ content in the Tb-Fe layers depends on the layer thickness. The thermal treatments promote the $\mathrm{Tb}$ enrichment of the $\mathrm{Tb}-\mathrm{Fe}$ layers in the heterostructures with thick layers, with precipitates not being formed. In the multilayers with thin layers, it appears that the strong lattice mismatch inhibits a complete $\mathrm{Tb}$ diffusion. Our experimental results indicate that there are potential magnetostrictive $\mathrm{TbFeGa}$ alloys in those samples.

\section{ACKNOWLEDGMENTS}

This work has been financially supported by Comunidad de Madrid and Universidad Complutense de Madrid through the project CCG10-UCM/MAT-4621. We thank "C.A.I. de Difracción de Rayos X" of the Universidad Complutense de Madrid for XRD measurements.

${ }^{1}$ A. E. Clark, J. B. Restorff, M. Wun-Fogle, T. A. Lograsso, and D. L. Schalgel, IEEE Trans. Magn. 36, 3238 (2000).

${ }^{2}$ Q. Xing and T. A. Lograsso, Appl. Phys. Lett. 93, 182501 (2008).

${ }^{3}$ H. Cao, F. Bai, J. Li, D. D. Viehland, T. A. Lograsso, and P. M. Gehring, J. Alloys Compd. 465, 244 (2008).

${ }^{4}$ H. Cao, P. M. Gehring, C. P. Devreugd, J. A. Rodríguez-Rivera, J. Li, and D. Viehland, Phys. Rev. Lett. 102, 127201 (2009).

${ }^{5}$ Y. Du, M. Huang, S. Chang, D. L. Schlagel, T. A. Lograsso, and R. J. McQueeney, Phys. Rev. B 81, 054432 (2010).

${ }^{6}$ M. Laver, C. Mudivarthi, J. R. Cullen, A. B. Flatau, W.-C. Chen, S. M. Watson, and M. Wuttig, Phys. Rev. Lett. 105, 027202 (2010).

${ }^{7}$ E. Arenholz, G. van der Laan, A. McClure, and Y. Idzerda, Phys. Rev. B 82, 180405 (2010).

${ }^{8}$ A. E. Clark, M. Wun-Fogle, J. B. Restorff, T. A. Lograsso, and J. R. Cullen, IEEE Trans. Magn. 37, 2678 (2001).

${ }^{9}$ J. H. Yoo, J. B. Restorff, M. Wun-Fogle, and A. B. Flatau, Smart Mater. Struct. 18, 104004 (2009).

${ }^{10}$ A. E. Clark and H. S. Belson, Phys. Rev. B 5, 3642 (1972).

${ }^{11}$ A. E. Clark, Appl. Phys. Lett. 23, 642 (1973).

${ }^{12}$ A. Javed, N. A. Morley, and M. R. J. Gibbs, J. Magn. Magn. Mater. 321, 2877 (2009) 
${ }^{13}$ N. A. Morley, A. Javed, and M. R. J. Gibbs, J. Appl. Phys. 105, 07 A912 (2009).

${ }^{14}$ R. R. Basantkumar, B. J. Hills Stadler, W. P. Robbins, and E. M. Summers, IEEE Trans. Magn. 42, 3102 (2006).

${ }^{15}$ B. W. Wang, S. Y. Li, Y. Zhou, M. W. Huang, and S. Y. Cao, J. Magn. Magn. Mater. 320, 769 (2008).

${ }^{16}$ R. A. Dunlap, N. C. Deschamps, R. E. Mar, and S. P. Farrell, J. Phys.: Condens. Matter 18, 4907 (2006).

${ }^{17}$ R. Ranchal, E. López, J. L. Prieto, and C. Aroca, Acta Mater. 59, 2865 (2011).
${ }^{18}$ O. Ikeda, R. Kainuma, I. Ohnuma, K. Fukamichi, and K. Ishida, J. Alloys Compd. 347, 198 (2002).

${ }^{19}$ Q. Xing, Y. Du, R. J. McQueeney, and T. A. Lograsso, Acta Mater. 56, 4536 (2008).

${ }^{20}$ R. E. Camley, Phys. Rev B 39, 12316 (1989).

${ }^{21}$ Y. Mimura, N. Imamura, T. Kobayashi, A. Okada, and Y. Kushiro J. Appl. Phys. 49, 1208 (1978).

${ }^{22} \mathrm{TbFe}_{2}: \mathrm{a}=\mathrm{b}=\mathrm{c}=7.3410 \AA$ A. $\mathrm{Fe}(\mathrm{bcc}): \mathrm{a}=\mathrm{b}=\mathrm{c}=2.8664 \AA$.

${ }^{23}$ Y. J. Tang, H. L. Luo, N. F. Gao, Y. Y. Liu, and S. M. Pan, Appl. Phys. Lett. 66, 388 (1995). 